\title{
A IMPLEMENTAÇÃO DA LEI DE ACESSO À INFORMAÇÃO PÚBLICA NO BRASIL E A CULTURA DO SIGILO: ANÁLISE DOS PORTAIS DO PODER EXECUTIVO FEDERAL
}

\section{THE IMPLEMENTATION OF THE BRAZILIAN LAW OF ACCESS TO INFORMATION AND THE CULTURE OF SECRECY: EVALUATION OF THE FEDERAL EXECUTIVE BRANCH ONLINE PORTALS}

Recebimento: 12 ago. 2019

Aceitação: 25 jan. 2021

\begin{abstract}
Pedro Afonso Domingos Silveira
Bacharel em Direito

Afiliação institucional: Universidade Federal de Santa Maria - UFSM - (Santa Maria, RS, Brasil)

Lattes iD: http://lattes.cnpq.br/7574032146585867

Email: pedroafonsosilveiraa@gmail.com

Rosane Leal da Silva

Doutora em Direito

Afiliação institucional: Universidade Federal de Santa Maria - UFSM - (Santa Maria, RS, Brasil)

Lattes iD: http://lattes.cnpq.br/1218962383221912

Email: rosane-leal.da-silva@ufsm.br
\end{abstract}

Como citar este artigo / How to cite this article (informe a data atual de acesso / inform the current date of access):

SILVEIRA, Pedro Afonso Domingos; SILVA, Rosane Leal da. A implementação da Lei de Acesso à Informação Pública no Brasil e a cultura do sigilo: análise dos portais do Poder Executivo Federal. Revista da Faculdade de Direito UFPR, Curitiba, v. 65, n. 3, p. 85-114, set./dez. 2020. ISSN 2236-7284. Disponível em: https://revistas.ufpr.br/direito/article/view/68473. Acesso $\quad$ em: $31 \quad$ dez. $2020 . \quad$ DOI: http://dx.doi.org/10.5380/rfdufpr.v65i3.68473.

\section{RESUMO}

Este estudo versa sobre a implementação da Lei no 12.527/2011 (Lei de Acesso à Informação Pública, ou LAI), analisando o cenário nacional de aplicação do direito fundamental representado por esse acesso, após a vigência da lei. Para tanto, utilizou-se o método de abordagem dedutivo, partindo-se dos conceitos de participação e controle social, governo aberto e governo eletrônico, além da importância do assunto para o exercício de novas dimensões da cidadania, intensificadas com o advento das Tecnologias de Informação e Comunicação (TIC). As técnicas de pesquisa bibliográfica e documental são complementadas pelo método de procedimento monográfico, a partir do qual foram eleitos e observados, de maneira sistemática e não participativa, os portais online do Poder Executivo no âmbito federal, englobando ministérios e a Presidência da República, a fim examinar de forma crítica os reflexos da LAI na realidade brasileira de acesso a dados, especialmente em razão da necessidade de superação da cultura do sigilo, ainda existente. A conclusão é de que a Lei $\mathrm{n}^{0}$ 12.527/2011, aliada às novas TIC, é um instrumento relevante para a democratização da informação, aproximando agentes públicos e sociedade. No entanto, há inconsistências na implementação da legislação, que ainda não foi capaz de sanar a carência de transparência pública. Verificou-se a necessidade de criação de procedimentos objetivos, transparentes e de fácil assimilação, a exemplo da atualização periódica das informações, bem como da padronização dos portais e maior 
concentração de dados nos próprios sites das entidades, para facilitar o empoderamento popular e a participação na política nacional.

\title{
PALAVRAS-CHAVE
}

Controle social. Cultura do segredo. Direito fundamental. Lei de Acesso à Informação.

\begin{abstract}
This study deals with the implementation of Law 12,527/2011 (Brazilian Law of Access to Information, or LAI), analyzing the national scenario, since the law came into force, for the application of the fundamental right represented by this access. For that, the deductive approach method was used, starting from the concepts of participation and social control, open government and electronic government, in addition to the importance of the subject for the exercise of new dimensions of citizenship, intensified with the advent of Information and Communication Technologies (ICT). The techniques of bibliographic and documentary research are complemented by the monographic procedure method, from which the online portals of the Executive Branch at the federal level, including ministries and the Presidency of the Republic, were chosen and observed, in a systematic and non-participatory manner, in order to critically examine LAI's reflexes in the Brazilian reality of data access, especially due to the need to overcome the culture of secrecy, which still exists. The conclusion is that Law 12,527/2011, combined with the new ICTs, is a relevant instrument for the democratization of information, bringing public agents and society closer together. However, there are inconsistencies in the implementation of the legislation, which has not yet been able to remedy the lack of public transparency. There is a need to create objective, transparent and easy to assimilate procedures, such as the periodic updating of information, as well as the standardization of portals and greater concentration of data on the entities' own websites, to facilitate popular empowerment and participation in national politics.
\end{abstract}

\section{KEYWORDS}

Social control. Culture of secrecy. Fundamental right. Brazilian Law of Access to Information.

\section{INTRODUÇÃO}

No cenário de democratização e sensível avanço tecnológico recente, o Brasil aderiu, na virada para o século XXI, à diretriz de governo eletrônico e aberto. As primeiras medidas adotadas se concentraram na operacionalização e informatização da administração pública, a partir da criação do Comitê Executivo de Governo Eletrônico. Vencida esta primeira etapa, as diretrizes que norteiam o tema deixaram de tomar o cidadão como cliente dos serviços prestados publicamente, considerandoo como produtor de ideias e participante na política. O crescente uso das Tecnologias da Informação e Comunicação (TIC), de um lado, e os esforços realizados na seara internacional em favor da adoção de padrões de governo aberto, de outro, produziram efeitos positivos sobre o cenário brasileiro.

Partindo dessa conjunção de fatores, editou-se a Lei $n^{0}$ 12.527/2011 - Lei de Acesso à Informação Pública (LAI), legislação que regulamenta o direito de acesso à informação pública previsto no ordenamento jurídico brasileiro no art. 50, XXXIII, bem como no art. 37, $\S 3^{\circ}$, II e art. 
216, § 2º da Constituição Federal de 1988. Segundo esse diploma legal, todos os cidadãos têm a prerrogativa básica de receber dos órgãos públicos informações particulares ou gerais, bem como de acesso a registros administrativos e atos do governo.

De acordo com os vetores da LAI, garantir o acesso à informação é dever do Estado, a partir de procedimentos objetivos, transparentes e de fácil assimilação. Sua incorporação ao ordenamento jurídico brasileiro constitui considerável incremento à democracia brasileira, visto que instrumentaliza o direito de acesso a dados públicos previsto na Carta Magna e impõe novos deveres e responsabilidades aos governantes, incumbidos de garantir a publicidade de dados, mantendo a sua disponibilidade, autenticidade e integridade. A tradicional maneira de se pensar a administração pública a partir do sigilo torna-se exceção, enquanto a cultura do acesso e publicidade torna-se, em teoria, a regra.

Contudo, tal imposição normativa contrasta com as crescentes notícias de práticas corruptas, a revelar os limites da legislação e sua dificuldade de implementação em face da recorrente imoralidade administrativa e da cultura do segredo que ainda se mantém. Esse empecilho é retratado em situações como a disponibilização precária de informações de caráter coletivo e incompetência na gestão dos entes públicos, fatores que geram descrédito da população em relação às instituições públicas e desesperança com os rumos do País, obstaculizando a participação social.

O distanciamento existente entre os princípios norteadores da LAI e a realidade brasileira marcada pela corrupção sugere que, inobstante a vigência de lei específica, a cultura do segredo e das tratativas escusas ainda se mostra constante nos órgãos públicos, a justificar a presente investigação.

Portanto, a motivação para a realização deste estudo faz-se pelo atual cenário nacional, com constantes questionamentos sobre a gestão pública e sua (in)eficiência, sendo necessário debater possíveis ações a fim de promover a transparência e boa governança. Tais medidas são condição de possibilidade para pensar o governo aberto, o que pressupõe a ampliação do acesso aos dados públicos, incremento da transparência ativa por parte dos gestores estatais, abertura para a participação popular na administração pública e agilidade dos processos com vista à maior eficiência nos serviços coletivos, beneficiando sensivelmente o cidadão.

A par dessas considerações, o presente trabalho discute o tema com o objetivo de averiguar a importância da Lei de Acesso à Informação no combate à cultura do sigilo e na adoção de modelo de gestão compartilhada de Estado, modificando a atual realidade de acesso a dados públicos no Brasil para, uma vez feita a abordagem teórica, analisar criticamente os dados sobre a implementação da legislação em comento. 
Para tanto, utilizou-se o método dedutivo, partindo-se de visão mais geral sobre a importância do acesso às informações públicas, em abordagem descendente até discutir a implementação da LAI nos portais online. Tal abordagem foi feita a partir do estudo de casos, consistente na análise dos sites dos ministérios e da Presidência da República, avaliados como mais relevantes à pesquisa. Foi aplicada observação direta, sistemática e não participativa, no intuito de averiguar a adequação dos portais à Lei de Acesso à Informação, bem como apontar as limitações apresentadas e as dificuldades na implementação da norma.

Em um primeiro momento, trata-se da mudança de papel do cidadão, que se torna participante ativo e fiscalizador do Estado a partir do uso das TIC e diretrizes de governo aberto e eletrônico. A segunda parte objetiva verificar e analisar a estrutura dos sites e portais objetos da pesquisa, discutindo-se a (in)eficiência da implementação da Lei de Acesso à Informação no Brasil, destacando-se o problema da cultura do sigilo, em detrimento da transparência, nos órgãos públicos. Na análise dos dados, enfatizam-se os seguintes fatores: a) transferência de responsabilidade dos órgãos em disponibilizar as informações em seu próprio site; $b$ ) licitações; $c$ ) receitas e $d$ ) contratos. A terceira seção destina-se às considerações finais e, na sequência, apresentam-se as referências bibliográficas.

\section{AS TECNOLOGIAS DE INFORMAÇÃO E COMUNICAÇÃO COMO INSTRUMENTO DE PROMOÇÃO DO GOVERNO ABERTO}

As mudanças ocorridas nas últimas décadas, sobretudo os avanços tecnológicos, têm relevância nos setores público e privado, bem como no contexto social, político e econômico. A crescente utilização dos recursos de comunicação reflete nas relações sociais, empresariais e institucionais. Em pesquisa recente foi constatado que, ao lado das mídias tradicionais principalmente televisão -, a Internet era o meio de maior influência para escolha, pelo eleitor, entre os candidatos à Presidência da República em 2018, conforme o IBOPE Inteligência (REDES..., 2017).

Na sociedade baseada na informação não há mais a possibilidade de separar as ações políticas e as Tecnologias de Informação e Comunicação (TIC) ${ }^{1}$. Como defendido por Lévy (1999, p. 79), “[...] sistemas que permitam o acesso compartilhado e à distância a documentos, fontes de informação ou espaços de trabalho nos aproximam progressivamente da comunicação por um mundo

\footnotetext{
1 Meios tecnológicos que implementam ou facilitam a comunicação. Exemplos: rede mundial de computadores, tablets, smartphones.
} 
virtual.” As teias informacionais contemporâneas possibilitam que qualquer informação seja disponibilizada instantaneamente e a cada dia ganham maior nível de complexidade.

Bernardes, Santos e Rover (2015, p. 763), atribuem essa latente tendência de utilização das novas tecnologias nas ações estatais a um movimento chamado Nova Gestão Pública (NGP), surgido na década de 1990. Seria, portanto, um direcionamento dos governos nacionais a fim de acompanhar as exigências do mercado de informatização dos serviços, orientando as práticas do setor público à maior eficiência.

Nesse movimento de abertura, a utilização das TIC tornou-se orientação comum nas prestações de serviços governamentais, pois viabiliza a constante disseminação de informações à sociedade, além de permitir a contínua discussão sobre assuntos em pauta no cenário político. Conforme Bonavides (2008), na nova era tecnológica, a vontade do povo deve ser ouvida ainda mais intensamente, conferindo legitimidade ao governo.

A modernização do País e da gestão pública proporcionam melhorias na qualidade e alcance de comunicação, eficiência no funcionamento da máquina governamental, transparência nos atos administrativos, fiscalização eficaz dos gestos políticos e maior exercício da cidadania. Todos esses benefícios são potencializados por meio da facilidade de acesso, na Internet, a serviços públicos.

Segundo Bernardes, Santos e Rover (2015, p. 763), a ideia de governo eletrônico, fundamentada pela Nova Gestão Pública, restringiu-se à função de aumentar a eficiência dos serviços, sem, no entanto, o devido foco na demanda atual de participação cidadã nas ações públicas. Buscouse dar, por esse motivo, maior teor democrático ao movimento de informatização do Estado, com o objetivo de aproximar a sociedade da gestão pública, retirando a população da posição apenas de receptora de ideias. Denhardt e Denhardt (2003) conferem ao movimento do Novo Serviço Público a função de evolução tecnológica como instrumento a ser colocado à disposição do cidadão, não mais como mero alocutário e sim como desenvolvedor de convicções. O foco principal dos autores é viabilizar a atuação ativa da população, de modo que exerçam sua cidadania plena.

Calderón e Lorenzo (2010) sustentam que a boa governança não dispensa determinadas características: abertura, transparência, flexibilidade e participação. Aduzem que o conceito de governo aberto é o de processo que fomenta a participação política do povo, por meio de transparência e responsabilidade dos gestores. Afirmam que o principal objetivo desse conceito de governo é o progresso da democracia, pois promove a cultura de colaboração social na prática política, uma vez que requer diálogo constante por parte dos governantes e processos de abertura de dados (Open Data). Portanto, não se trata apenas de publicizar dados de modo compreensível e seguir os ditames da LAI, mas de possibilitar ao coletivo conhecer dos procedimentos administrativos desde as suas concepções, 
bem como de interagir com esses procedimentos e posicionar-se sobre eles (CALDERÓN; LORENZO, 2010) - comportamentos que podem contribuir para o combate à corrupção.

O envolvimento da sociedade e sua participação mais ativa na gestão pública, bem como seu conhecimento acerca das relações entre os gestores públicos e os dirigentes das pessoas jurídicas de direito privado, revelam-se medidas essenciais para o combate aos desvios e à má utilização de bens públicos, tal como evidenciado no texto da Convenção das Nações Unidas contra a Corrupção, adotada pela Assembleia Geral das Nações Unidas em 31 de outubro de 2003 e ratificada pelo Brasil por meio do Decreto $n^{0}$ 5.687, de 31 de janeiro de 2006 (BRASIL, 2006).

Neste importante compromisso internacional, os Estados Partes, entre eles o Brasil, mostram-se "Convencidos de que a corrupção deixou de ser um problema local para converter-se em um fenômeno transnacional que afeta todas as sociedades e economias” - dimensão global que exige cooperação internacional a ser empreendida por distintos atores. Uma das apostas da Organização das Nações Unidas (ONU) já vem expressa no preâmbulo do documento e se refere à prevenção. Para tanto é necessária a cooperação não só dos Estados entre si, mas também o “[...] apoio e a participação de pessoas e grupos que não pertencem ao setor público, como a sociedade civil, as organizações nãogovernamentais e as organizações de base comunitárias, para que seus esforços neste âmbito sejam eficazes” (BRASIL, 2006).

A íntima conexão entre as práticas de transparência e prestação de contas, consideradas medidas indispensáveis à prevenção da corrupção, já se revelam no início do documento, em seu art. 5, no qual se evidencia o compromisso dos Estados:

1. Cada Estado Parte, de conformidade com os princípios fundamentais de seu ordenamento jurídico, formulará e aplicará ou manterá em vigor políticas coordenadas e eficazes contra a corrupção que promovam a participação da sociedade e reflitam os princípios do Estado de Direito, a devida gestão dos assuntos e bens públicos, a integridade, a transparência e a obrigação de render contas (BRASIL, 2006).

Ainda que o País tenha feito parte do grupo dos países signatários da Convenção e a tenha ratificado, fez alguns avanços no sentido de abertura do governo sem, todavia, editar lei específica de acesso à informação. Não obstante, com o objetivo de progredir no cenário de governo aberto, o Brasil assinou, em setembro de 2011, a “Declaração de Governo Aberto”, ferramenta que buscou fortalecer as ideias de transparência e participação cívica. No instrumento, é reconhecida a responsabilidade de “dominar o poder das novas tecnologias para tornar o governo mais efetivo e responsável”, referência às diretrizes de governo eletrônico (CONTROLADORIA-GERAL DA UNIÃO, 2011). Além disso, é destacada a necessidade de promover os princípios de governo aberto, apoiando "participação 
pública de todos, igual e indiscriminadamente, no processo de tomada de decisões e formulação de políticas” (CONTROLADORIA-GERAL DA UNIÃO, 2011).

Para além do disposto nessa declaração, Bernardes, Santos e Rover (2015, p. 765) explicam que a ideia de governo aberto se torna relevante porque traz à tona conceitos de transparência, colaboração e participação, possibilitando ao cidadão, por meio das informações e das diretrizes de governo eletrônico, deixar de ser sujeito receptor e consumidor. Com essas medidas, a população pode deixar a condição passiva na relação com o Estado, passando a detentor do poder de fiscalizar e questionar, o que poderá conferir nova dimensão ao exercício da cidadania. A referida abertura também auxilia na consolidação da legitimidade dos governantes perante a população, já que a transparência das ações remete à lisura e credibilidade do órgão público.

A transparência informacional na gestão deve abranger toda a organização da gestão pública, tanto em relação à divulgação de suas ações, quanto na publicidade de sua atuação interna, em nome da transparência e em respeito à função pública de servir à sociedade. É o que se depreende do documento produzido pela Organização das Nações Unidas (2016), no sentido de que, além da prestação de serviços públicos, um dos principais direitos que podem ser ampliados com a adoção das tecnologias pela administração pública é a garantia do acesso à informação pública. Justifica-se o discurso das Nações Unidas, uma vez que o acesso a esses dados constitui um direito humano fundamental inerente à democracia.

Somando-se à ONU, diversas outras instituições internacionais relevantes na promoção dos direitos humanos, sob o escopo de proteção à liberdade de expressão, passaram a reconhecer o direito fundamental de acesso à informação pública, bem como a sua instrumentalização interna por meio de legislações competentes, conforme Mendel (2009).

Quanto a isso, é essencial o entendimento do Comitê Gestor de Internet no Brasil (CGIB) (MARTINHÃO, 2018, p. 97)², de que é salutar a consolidação de um “instrumento sistemático de mensuração que permita compreender a incorporação das tecnologias pelos órgãos públicos e seu uso na oferta de serviços públicos”. Esses mecanismos devem atuar como forma de praticar a cultura de governo aberto no Brasil. Ainda conforme o órgão referido, é necessária a criação de instrumentos de participação social que facilitem o acesso à informação, de modo a tornar viável o uso das novas tecnologias nos setores estatais.

Cria-se assim a incumbência dos gestores para disponibilizarem constantemente meios para o acesso a todo e qualquer dado de relevância pública. Em outras palavras, os órgãos atuantes em

2 Ressalta-se que o Decreto 9.759, de 11 de abril de 2019, extinguiu, entre outros órgãos, o Comitê Gestor da Internet no Brasil. 
assuntos como ações coletivas, segurança - nesse ramo, ressalvam-se as informações sigilosas relacionadas à segurança nacional -, saúde, educação, bem como qualquer outro tema referente a direitos fundamentais individuais e coletivos possuem a obrigação de disponibilizar as informações para o cidadão.

O crescente compromisso de responsabilidade ao qual o governante está exposto é consequência da publicidade, pois, à medida que seus atos, decisões e comportamentos são cada vez mais evidenciados, tanto haverá maior observação sobre suas ações, quanto maior fiscalização e controle social.

A participação e a consensualidade, por consequência, tornam-se decisivas para as democracias contemporâneas. Moreira Neto (2000, p. 12) destaca que essas atitudes contribuem para melhorar a governabilidade, garantir a legalidade e atenção ao interesse populacional. Propiciam a legitimidade das ações políticas, uma vez que incrementam a responsabilidade dos agentes sociais, tornando os atos do Estado acessíveis e legitimados.

Quanto mais a população tiver acesso aos dados de interesse coletivo, maior será sua participação nas decisões políticas e, consequentemente, cobrará responsabilidade dos agentes públicos em suas ações. O resultado dessa combinação poderá conduzir a gestões públicas mais éticas e eficazes, com possibilidade de promoção de verdadeira mudança na atuação dos agentes políticos.

Martins Júnior (2004) entende que a participação social na gestão coletiva é uma das bases do Estado Democrático de Direito, pois a partir da participação a sociedade também exerce o controle social. O cidadão legitima as ações do Estado a partir do momento que se torna parte ativa da construção comunitária, construindo coletivamente um saber político, compreendendo o espectro social e atuando para muito além do voto a cada quatro anos.

Corroborando esta importância do saber na participação social, Werthein (2000, p. 71-72) compara as revoluções industriais, incentivadas por novas fontes energéticas, proporcionando visíveis mudanças sociais, com a revolução tecnológica atual, impulsionada pelo intenso avanço da informação. Essa comparação é pertinente para a percepção da mudança abrupta que um centro social sofre com a implementação dos novos meios comunicacionais, estimulada pela evolução informacional. Quanto mais dados forem proporcionados e quanto maior for a qualidade dessa disposição à população, mais qualificada será sua participação nas decisões políticas e maior será a exigência de responsabilidade dos agentes públicos em suas ações.

Não é sem razão que o art. 37 da Carta Magna de 1988 do Brasil dispõe que toda a administração pública direta, indireta ou fundacional, de qualquer dos Poderes da União, do Estado, do Distrito Federal e dos Municípios obedecerá ao princípio da legalidade, impessoalidade, 
moralidade, publicidade e eficiência. Baseado tanto na Constituição Federal quanto na Lei de Acesso à informação - posteriormente estudada -, é imprescindível a difusão de todas as ações dos agentes públicos que, de maneira implícita ou explícita, representam os interesses coletivos.

Ainda sobre a pertinência da publicidade, a Artigo 19³ (ARTICLE19, 2017, p. 14), em uma análise sobre transparência nos assuntos de segurança pública, sustenta que a publicidade não só é dever constitucional dos administradores na gestão pública, como o acesso à informação é direito constitucional do cidadão. Portanto, a população deve contar com todas as ferramentas necessárias para melhor posicionamento acerca dos assuntos de interesse público. A legítima participação popular é concretizada a partir do controle social, uma vez que quanto maior a gerência sobre os atores políticos, maior será a eficiência de suas práticas.

Nesse mesmo sentido, a Controladoria-Geral da União (2008, p. 16) define o controle social como a participação pelo povo na gestão e na fiscalização das ações da administração pública, tornando-se um importante instrumento na prevenção da corrupção e no fortalecimento da cidadania. Este posicionamento mostra-se em harmonia com o disposto por alguns doutrinadores, entre eles Cardoso (1998), para quem o Estado precisa atuar de maneira diferente, pois além de eficiente, necessita estar orientado por valores gerados pela própria sociedade, capaz de comunicar-se com o público de forma desimpedida.

Acrescenta-se a isso o fato de que a transparência das ações e condutas governamentais não deve ser apenas um flatus vocis, um discurso vazio, mas sim um comportamento constante. A divulgação de informações seguramente contribui para evitar episódios lesivos e prejudiciais aos cidadãos.

Formar um sistema que privilegie a divulgação não só legitima o cidadão a fiscalizar os atos públicos, como também é uma forma de controle em si, pois permite a diferenciação entre o que beneficia o interesse popular e as ações que o contrariam (BOBBIO, 1997). A preponderância do princípio da publicidade administrativa é um excelso modo de concretizar a república enquanto forma de governo. O modo republicano de organização da gestão pública brasileira deve somar-se à sua outra metade, qual seja, o direito do cidadão de ter sua nação republicanamente gerenciada. É passível de caos uma administração pública que não seja baseada no princípio da publicidade.

Como demonstrado, é desejável que a publicização seja a regra de qualquer ato público que reflita na sociedade, caracterizando o governo aberto. Para haver a discussão social eficaz, é

3 A Artigo 19 (no original, ARTICLE ${ }^{19}$ ) é uma organização não governamental de direitos humanos fundada em Londres e voltada à promoção do direito à libertade de expressão e defesa do acesso à informação, com atuação em inúmeros países. 
necessária a difusão geral de informações de caráter geral. Explica de la Rue (2013) que o saber político permite ao indivíduo melhores instrumentos para a construção de argumentos hábeis a discutir as ações de seus representantes, possibilitando maior gerência popular na construção do Brasil e desconcentrando da minoria o poder de participação, pertinente a toda a população.

Ter conhecimento sobre as práticas governamentais, em todos os graus de regência, viabiliza a elaboração de uma política social no País, processo que deve ser colocado em marcha tanto por gestores quanto pela população. Assim, não se pode creditar as importantes transformações que o País necessita à mera existência de tecnologias. Em analogia extensível ao Poder Executivo, e conforme destacado por de la Rue (2013, p. 104), as TIC “[...] não podem ser vistas como aquelas que irão solucionar repentinamente todos os problemas de falta de legitimidade e descrença com o Poder Legislativo”.

Corroborando o exposto, é indispensável a explicação de Castells (2006, p. 19):

[...] a questão não é como chegar à sociedade em rede, um auto-proclamado estádio superior do desenvolvimento humano. A questão é reconhecer os contornos do nosso novo terreno histórico, ou seja, o mundo em que vivemos. Só então será possível identificar os meios através dos quais, sociedades específicas em contextos específicos, podem atingir os seus objectivos e realizar os seus valores, fazendo uso das novas oportunidades geradas pela mais extraordinária revolução tecnológica da humanidade, que é capaz de transformar as nossas capacidades de comunicação, que permite a alteração dos nossos códigos de vida, que nos fornece as ferramentas para realmente controlarmos as nossas próprias condições, com todo o seu potencial destrutivo e todas as implicações da sua capacidade criativa.

A Internet e demais tecnologias são, portanto, instrumentos, mas nunca um fim em si mesmas, pois quem deve conferir legitimidade aos processos democráticos são os agentes políticos e a participação dos cidadãos, indo ao encontro do sistema de governo eletrônico e de abertura.

O que se busca elucidar é a importância de disponibilizar as informações e ferramentas digitais de modo que qualquer pessoa tenha acesso. Viabilizar portais de fácil acesso e navegação, com linguagem simples e atualizada são imprescindíveis para os cidadãos, possibilitando o diálogo e intervenção nas ações do Estado.

Ferreira e Araújo (2000) explicam que a utilização da rede mundial de computadores e websites governamentais como instrumento de prestação de serviços e informações online, com dados das atividades públicas, constitui uma forma de alçar a eficácia e a qualidade das ações prestadas ao cidadão. Ainda segundo os autores, esses institutos possibilitam acolher necessidades específicas da população, suscitando maior participação na gestão pública, determinando preferências e fiscalizando os governos. 
O direito de acesso à informação é, como se vê, um expressivo canal de auxílio na obtenção de conhecimento, sendo imprescindível um serviço público eficiente e transparente para a implantação desse direito (MELLO; CALLEGARI, 2012, p. 2). A partir da modernização da gestão pública e da instauração de um governo aberto, torna-se facilitada a presença dos cidadãos na discussão das questões de interesse político e coletivo. Consequentemente, viabiliza-se a cidadania ativa.

Bobbio (1997, p. 30, grifo do autor), sobre o assunto, relembra o argumento de que o único modo de "fazer com que um súdito transforme-se em cidadão é o de lhe atribuir aqueles direitos que os escritores de direito público do século passado [XIX] tinham chamado de activae civitatis" - do latim, cidadania ativa. Assim, para o jusfilósofo italiano, a democracia só surge e se legitima quando da própria prática da democracia, aguçando a participação cidadã para além dos laços de eleição, com discussões fundamentadas e fiscalização das ações políticas.

Partindo-se da ideia de cidadão ativo, surge o questionamento: quem controla os controladores? Apesar de não se tratar de questão simples, não encontrar resposta para ela coloca o sistema democrático em jogo, invertendo a máxima necessária de poder do povo sobre o Estado (BOBBIO, 1997). A democracia é feita por meio de ações contínuas dos cidadãos, desde o voto a cada período eleitoral até a discussão constante das pautas políticas debatidas no cenário público.

Da mesma maneira, expõe Paes de Paula (2005, p. 44, grifo nosso):

[...] um aparelho do Estado com características participativas deve permitir a infiltração do complexo tecido mobilizatório, garantindo a legitimidade das demandas populares. Para isso é necessário criar arranjos institucionais que organizem a participação nas diferentes esferas governamentais, e que estas sejam dinâmicas o suficiente para absorver as tendências cambiantes inerentes à democracia. É importante ressaltar que a concretização dessas mudanças depende da maneira como o Estado e a sociedade brasileira se articulam para determinar seus papéis e espaços.

A melhor maneira de oportunizar essas atitudes para que o "súdito transforme-se em cidadão” é mediante a realização de um governo aberto, no qual a transparência seja a regra, o pilar da administração pública. Aliás, a criação de condições materiais de acessibilidade confere força normativa ao princípio constitucional da publicidade, torna o cidadão mais próximo da sua real função social dentro de um Estado democrático, qual seja, a de participante ativo.

Nessa linha, é primordial a abertura das instituições políticas à participação social e à construção de canais de interação popular, proporcionadas pela aplicação da LAI. Segundo explicação de Paes de Paula (2005, p. 44), leis dessa natureza permitem a inclusão de setores marginalizados na deliberação de assuntos de interesse público, além de proporcionarem um debate transparente e aberto à expressão do povo. 
É evidente, no entanto, que há um distanciamento entre os princípios legais e as finalidades da lei e sua efetivação, que exige mudanças comportamentais e adoção de novo modus operandi pelos gestores públicos. É exatamente para desvelar essa realidade que se avança no próximo item, cujo objetivo é discutir a implementação da LAI.

Uma vez vencida a análise teórica acerca da importância das diretrizes de governo eletrônico, governo aberto, aliados às TIC, para ensejar maior participação cívica e controle social no cenário político, parte-se para o enfoque prático. Examina-se, a partir de agora, a implementação da Lei de Acesso à Informação nos órgãos do Poder Executivo Federal, verificando a estrutura dos sites e portais objetos da pesquisa, discutindo-se a (in)eficiência da implementação da LAI no Brasil e destacando o problema da cultura do sigilo, em detrimento da transparência, nos órgãos públicos.

\section{A IMPLEMENTAÇÃO DA LEI DE ACESSO À INFORMAÇÃO NOS SITES DO PODER EXECUTIVO FEDERAL}

A Lei de Acesso à informação foi apresentada à população brasileira com a promessa de constituir-se em importante instrumento de promoção da transparência dos órgãos públicos. Vigente desde 2012, a norma regula o acesso a informações, conforme previsto no inciso XXXIII do art. 5ำ da Constituição Federal, e tem como seu fundamento a disponibilização ampla de dados públicos que, em sua maioria, não são disponibilizados ao grande público. A promulgação da lei visa potencializar o acesso informacional à sociedade, pois desafia a cultura de monopolização do poder estatal em relação à formulação e discussão das políticas públicas. É salutar, então, o debate acerca da implementação da LAI no Brasil.

Manter o cidadão bem-informado e conscientizado acerca da realidade pública à sua volta é instrumento necessário para o combate à má administração e corrupção que assola o cenário político atual. Como sustentado por Bonavides (1997), a opinião pública, no sentido de conjunto de diálogos embasados e exteriorizados no meio social, é capaz de produzir força de massas. A partir do momento em que, auxiliado pelas novas técnicas de comunicação, a informação deixa de pertencer a uma classe privilegiada de políticos e gestores públicos, a fiscalização e a participação se legitimam como instrumentos de controle social. Em um modelo democrático, o gestor possui a obrigação de prestação de contas (MENDEL, 2009).

Quanto à forma de cumprimento dessa obrigação, a LAI prevê duas formas de transparência: passiva e ativa. Conforme Sousa (2014, p. 2), a primeira trata da disseminação de dados mediante requerimento do cidadão, sendo irrelevante que o requerente justifique a solicitação. A segunda 
espécie baseia-se na divulgação proativa de informações pelos órgãos públicos, que agem de maneira espontânea e sem guardar relação com requerimento específico.

Examinou-se, então, à luz da transparência ativa e da Lei $\mathrm{n}^{0}$ 12.527/2011, por meio de formulário previamente construído, os portais da Presidência da República e dos ministérios elencados como mais importantes para o cumprimento de direitos fundamentais e sociais, a exemplo de saúde, educação, trabalho e esporte.

O objetivo foi discutir, a partir de observação direta, sistemática e não participativa dos sites, a (in)eficiência da implementação da Lei de Acesso à Informação no Brasil, destacando o problema da cultura do sigilo, em detrimento da transparência, nos órgãos públicos. De modo a otimizar a análise foram selecionadas quatro categorias para o desenvolvimento, quais sejam: a) transferência de responsabilidade dos órgãos em disponibilizar as informações em seu próprio site; $b$ ) receitas; $c$ ) licitações e $d$ ) contratos.

Foram excluídos da pesquisa o Ministério da Pesca e Aquicultura e o Ministério da Previdência Social, extintos antes da análise e incorporados a pastas do Ministério da Agricultura, Pecuária e Abastecimento e Ministério do Trabalho, respectivamente.

A observação deu-se de oito de agosto de 2018 a 13 de dezembro de 2018, nos portais de 18 ministérios e da Presidência da República, destacando-se quatro tópicos elencados para o presente trabalho. Com o intuito de facilitar a compreensão, os resultados serão retratados em separado, apresentando-se individualmente cada categoria.

\subsection{TRANSFERÊNCIA DE RESPONSABILIDADE DOS ÓRGÃOS EM DISPONIBILIZAR AS INFORMAÇÕES NO SEU PRÓPRIO PORTAL}

Em análise do primeiro item, a pesquisa apresentou um problema intrínseco no método de disponibilização de dados nos portais. O assunto é relevante, uma vez que a padronização das informações dos órgãos públicos dentro de seus próprios sites é essencial para facilitar o acesso ao cidadão, diminuindo o caminho a ser percorrido para obter o conteúdo almejado.

No entanto, a incumbência de disponibilizar o dado, que deveria ser dos portais dos ministérios, é transferida ao Portal da Transparência. Com raras exceções, os sites examinados remetem muitas de suas informações ao Portal. Assim, a análise se limita à atuação de um sítio eletrônico, quando deveria ser de âmbito geral, com participação e cumprimento por parte de todos os órgãos do Poder Público. 
No site do Ministério das Relações Exteriores, informações de despesas, servidores e suas remunerações, convênios, viagens a serviço e servidores terceirizados são delegadas ao Portal da Transferência, sem constar qualquer orientação ao usuário acerca de como proceder à consulta. Essa sistemática, referente aos mesmos assuntos, foi verificada no Ministério do Planejamento, Desenvolvimento e Gestão ${ }^{4}$, Ministério do Esporte $^{5}$, Ministério da Educação, Ministério do Trabalho $^{6}$, Ministério da Saúde, Ministério da Agricultura, Pecuária e Abastecimento, Ministério da Cultura $^{7}$, Ministério da Indústria, Comércio Exterior e Serviços ${ }^{8}$ e no portal da Presidência da República.

A maneira de gerir os dados, exposta acima, reiterada nos sites de vários ministérios e da Presidência, aponta a padronização da prática de transferência de responsabilidade dos órgãos públicos em disponibilizar suas informações. Atitudes como essa, em um ambiente que já sofre com abundantes práticas corruptas, dificulta ainda mais o combate à cultura do segredo, uma vez que impõe diversos obstáculos ao cidadão interessado no conteúdo.

O exagero no uso de hiperlinks para remeter ao Portal da Transparência impõe uma capacidade interativa de quem busca os dados, o que é inconcebível na promoção da transparência ativa, pois entrava a possibilidade de qualquer pessoa acessar o teor dos dados, constrangendo o cidadão a percorrer um caminho de site em site, até que lhe seja provido o conteúdo. Fere, além de tudo, o art. $5^{\circ}$ da Lei $n^{\circ} 12.527 / 2011$, pois não garante “acesso à informação, que será franqueada, mediante procedimentos objetivos e ágeis, de forma transparente, clara e em linguagem de fácil compreensão”.

Da análise do Ministério da Defesa retiram-se pontos positivos. Apesar de o portal remeter o internauta ao Portal da Transparência, utiliza esse mecanismo como alternativo, tendo como principal meio de divulgação seu próprio site. Disponibiliza, de maneira geral, proativamente as informações necessárias, à exceção das informações sobre receitas, licitações e contratos, quando transfere a incumbência de informação a outro sítio eletrônico. Apesar disso, elucida de maneira didática qual caminho o cidadão deve seguir para encontrar a informação no site remetido, prática

4 Em 15 de outubro de 2018, data da realização da pesquisa no portal, o órgão ainda possuía a constituição de ministério. Atualmente, integra a pasta do Ministério da Economia.

5 Em 27 de novembro de 2018, data da realização da pesquisa no portal, o órgão ainda possuía a constituição de ministério. Atualmente, integra a pasta do Ministério da Cidadania.

6 Em 15 de outubro de 2018, data da realização da pesquisa no portal, o órgão ainda possuía a constituição de ministério. Atualmente, integra a pasta do Ministério da Economia.

7 Em 19 de novembro de 2018, data da realização da pesquisa no portal, o órgão ainda possuía constituição de ministério. Atualmente, integra a pasta do Ministério da Cidadania.

8 Em 18 de agosto de 2018, data da realização da pesquisa no portal, o órgão ainda possuía constituição de ministério. Atualmente, integra a pasta do Ministério da Economia. 
comum no portal do Ministério do Desenvolvimento Social ${ }^{9}$. Também se mostrou positiva a análise quanto aos dados acerca dos contratos no Ministério da Cultura, atualizados desde 2004, atuando de maneira proativa na disponibilização dos dados e sem transferir o cidadão a outros portais.

Como destaque negativo, no tocante ao item “convênios”, o Ministério da Saúde disponibiliza um hiperlink para acesso ao conteúdo em outro site. No entanto, a disposição do link é falha, levando o interessado a uma página inexistente. Em situação semelhante se encontra o item “execução de despesas” no site do Ministério do Trabalho, endereçando o cidadão ao Portal da Transparência por meio de um link expirado, que apresenta a mensagem “error 404”. No sítio do referido ministério ocorre o mesmo problema em relação às informações classificadas ${ }^{10}$, pois remete a uma página inexistente, situação que impossibilita ao interessado observar quais informações são tidas como sigilosas, bem como motivo e prazo de sigilo. Quarta ocasião análoga foi percebida nas informações sobre execução de despesas no portal do Ministério do Desenvolvimento Social, tornando impossível o acesso aos valores, itens e forma de utilização dos recursos.

Conclui-se que os órgãos, na tentativa de transferir a responsabilidade de publicização ao Portal da Transparência, tornam a informação inacessível, uma vez que não a expõem e nem proporcionam canal minimamente eficaz para fazê-lo.

O Ministério do Planejamento, Desenvolvimento e Gestão, em relação às “auditorias”, não remete a nenhum outro sítio eletrônico. No entanto, a última atualização dos dados deu-se em 2016. São três anos em que um órgão competente para gestão de interesses públicos não publiciza informações sobre as atividades desenvolvidas. Essa prática viola o disposto no art. $8^{\circ}$, § $3^{\circ}$, inciso VI, da Lei de Acesso à Informação Pública, em virtude de não manter atualizadas as informações disponíveis para acesso, além de ser exemplo claro de apropriação da cultura do segredo por parte do Poder Público.

A gravidade da conduta e o descaso com o cumprimento da lei conduzem Martins (2004, p. 177) a afirmar que

Trata-se, pois, de combater o princípio da arcana práxis, ou princípio do segredo, que, sendo próprio do Estado de polícia, não deixa, contudo, de manifestar a sua permanência no Estado de Direito no atuar de uma burocracia que procura encerrar-se em uma prática esotérica de difícil acesso ao cidadão comum.

\footnotetext{
9 Em 11 de novembro de 2018, data da realização da pesquisa no portal, o órgão ainda possuía a constituição de ministério. Atualmente, integra a pasta do Ministério da Cidadania.

10 Rol de informações do órgão classificadas como sigilosas dentro do disposto na Lei de Acesso à Informação.
} 
A cultura do sigilo, exemplificada acima, é um grande (se não o maior) obstáculo para a implementação das diretrizes de transparência necessárias em um Estado Democrático de Direito, inclusive em relação à LAI.

Conclui-se da análise desse tópico que os órgãos detentores das informações públicas tendem a manter como regra a cultura do sigilo na administração do País, pois transferem sua responsabilidade de publicização a outros órgãos, desconcentrando a informação pública. Consequência é a falta de padronização nos mecanismos de busca dos dados, bem como a dispersão do conteúdo referente a certo órgão em portais distintos, tornando inviável o acesso pelo cidadão.

Reiterando a importância no combate à regra do sigilo, Khan (2009, p. 1, grifo nosso) ensina:

É fundamental, para a garantia do livre fluxo das informações e das ideias, o princípio de que os órgãos públicos detenham informações não para eles próprios, mas em nome do povo. Esses órgãos possuem uma imensa riqueza de informações que, caso seja mantida em segredo, o direito a [sic] liberdade de expressão, garantido pela legislação internacional, bem como pela maioria das constituições, fica gravemente comprometido.

No entanto, a práxis muitas vezes não é efetivada. Não há padronização do Serviço de Informações ao Cidadão (SIC), ou seja, não há ações de sistematização das informações requeridas constantemente pela população, o que produziria a catalogação dos pedidos mais frequentes e, consequentemente, priorizaria a transparência ativa sobre a passiva, fator que facilitaria a exposição dos dados ao público e relativizaria o número de solicitações de acesso requestando as mesmas informações.

Vencida a análise acerca do primeiro item de estudo, serão evidenciados os mecanismos de acesso à informação em relação às receitas.

\subsection{A ABERTURA DOS DADOS SOBRE RECEITAS}

No que diz respeito ao segundo item selecionado para análise, novamente foram constatados problemas na gestão das informações. Uma vez que as receitas são valores recebidos pela unidade e incorporados ao seu patrimônio para custeio das despesas e investimentos públicos em prol da sociedade, é imperativo que sejam publicizadas informações a seu respeito, de modo eficiente. Do contrário, não há possibilidade de análise da maneira como o órgão ocupa seus recursos, em 
comparação com o quanto arrecada. Porém, o resultado da observação, ainda mais insatisfatório que a conclusão do primeiro tópico, apontou que 12, dos 19 órgãos, não tratam do assunto.

O Ministério da Educação nem sequer possui ‘aba’ para acesso à informação de receitas, assim como o Ministério da Ciência, Tecnologia, Inovações e Comunicações, Ministério da Fazenda ${ }^{11}$ e a Presidência da República. Situação semelhante foi apurada no site do Ministério da Indústria, Comércio Exterior e Serviços ${ }^{12}$, estendendo-se a omissão de informações às ações e programas, serviços à população e participação social.

O site do Ministério da Agricultura, Pecuária e Abastecimento, no que concerne às receitas, é um exemplo positivo. Apresenta planilha estruturada e atualizada desde 2008, com informações de natureza da arrecadação, origem, valores parciais e totais, tanto em análise mensal quanto anual.

No caso do portal do Ministério da Saúde, verifica-se boa estrutura referente às despesas, consistente em uma seção denominada “Sala de Apoio à Gestão Estratégica”, com discriminação atualizada e dividida dos gastos vinculados ao Sistema Único de Saúde (SUS). Porém, não trata sobre a receita do órgão, ferindo sensivelmente princípios tanto de acesso à informação quanto de gestão administrativa.

Alguns portais possuem um ícone intitulado "Receitas", todavia sem constar qualquer informação sobre o assunto. Exemplos são os sites do Ministério do Trabalho e do Ministério do Meio Ambiente, que possuem em seus menus principais os atalhos "Receitas e Despesas”. Seguindo os atalhos, encontra-se apenas acesso, via Portal da Transparência, às despesas, execução orçamentária e diárias e passagens, sem, no entanto, informações sobre as receitas dos órgãos.

Nos sete órgãos que tratam de algum modo sobre receitas, novamente foi constatado o problema de transferência de responsabilidade para o Portal da Transparência. É o caso do Ministério da Justiça ${ }^{13}$, Ministério do Turismo, Ministério de Minas e Energia, Ministério do Desenvolvimento Social e Ministério da Cultura ${ }^{14}$, que possuem links remetendo ao referido portal, mas sem propiciar informações de como o internauta conseguirá encontrar o dado no site remetido. O Ministério da

11 Em 28 de setembro de 2018, data da realização da pesquisa no portal, o órgão ainda possuía a constituição de ministério. Atualmente, integra a pasta do Ministério da Economia.

12 Em 18 de agosto de 2018, data da realização da pesquisa no portal, o órgão ainda possuía a constituição de ministério. Atualmente, integra a pasta do Ministério da Economia.

13 Em 18 de agosto de 2018, data da realização da pesquisa no portal, o órgão ainda denominava-se Ministério da Justiça. Atualmente sob a constituição de Ministério da Justiça e Segurança Pública.

14 Em 18 de agosto de 2018, data da realização da pesquisa no portal, o órgão ainda possuía a constituição de ministério. Atualmente, integra a pasta do Ministério da Cidadania. 
Defesa e o Ministério dos Transportes, Portos e Aviação Civil ${ }^{15}$, apesar de aderirem a essa sistemática, disponibilizam instruções detalhadas e didáticas para o cidadão obter o dado desejado.

A observação acerca do item “receitas” leva à conclusão de que os órgãos do Poder Executivo Federal trazem à prática poucos princípios de acesso à informação, não o implementando plenamente. Os dados, quando disponibilizados, são-no de maneira precária e desorganizada, estabelecendo-se ainda mais a cultura do segredo na administração dos recursos do País.

Tendo como base a necessidade de acesso da população sobre dados de interesse público para uma correta decisão, explicita-se um importante empecilho na imposição prática da lei em questão: a dificuldade imposta pelos órgãos públicos brasileiros em ceder as informações de caráter coletivo. Apesar de a publicidade ser, em teoria, um dos princípios da administração pública, devendo o segredo ser exceção, a realidade é diferente.

Percebe-se, sobremaneira, a inexistência de verdadeiro diálogo entre os Poderes Legislativo e Executivo. A necessidade de legislação é detectada e há a produção legislativa, porém no momento de sua aplicação efetiva, os princípios normativos esbarram na realidade burocrática da política brasileira.

Realidade como a exposta na análise acerca das informações sobre receitas nos órgãos do Poder Executivo Federal apenas corroboram a obstaculização da implementação da norma pelos próprios Poderes, sobre os quais os preceitos normativos deveriam surtir efeito. Tal procedimento resulta em descumprimento, o que impacta os objetivos finais da LAI, de combate à cultura do segredo e participação popular na construção política.

Uma vez apresentados os resultados obtidos sobre receitas, na sequência serão apresentados os dados sobre o tema da licitação.

\subsection{AS INFORMAÇÕES SOBRE LICITAÇÕES}

A incumbência de divulgação de informações acerca de licitações é percebida no art. $7^{\circ}$, § $3^{\circ}, \mathrm{V}$, do Decreto $n^{\circ} 7.724 / 2012$, que regulamenta a Lei de Acesso à Informação. Debruçar-se sobre o assunto é pertinente, uma vez que é por meio das licitações que ocorrem as contratações de serviços e a aquisição de bens pela administração pública, tendo como principal objetivo alcançar o melhor custo-benefício para o Estado. Por isso, é relevante estudar a maneira como são publicizadas as informações sobre o tema, pois trata-se de um instrumento de utilização do dinheiro público e,

15 Em 23 de setembro de 2018, data da realização da pesquisa no portal, o órgão ainda possuía a constituição de ministério. Atualmente, integra a pasta do Ministério da Infraestrutura. 
portanto, passível de práticas corruptas. Uma vez exposta a justificativa para a escolha do terceiro item, passa-se à exposição dos resultados.

A análise apresentou resultado melhor que os itens anteriores, com mais conclusões positivas acerca da implementação da LAI, sem, no entanto, eximir de falhas os portais que violam a normativa de acesso à informação.

De maneira geral, os portais não apresentaram atalho para solicitação, por meio de correio eletrônico, de informações adicionais acerca das licitações, tais como atas, anexos e projetos básicos.

O Ministério das Relações Exteriores mantém em seu portal dados desatualizados desde 2016, violando gravemente as disposições da Lei nº 12.527/2011, uma vez que dificulta a obtenção do conteúdo por parte do interessado. Consequência é o desconhecimento relativamente à maneira que o órgão investe seus recursos, impossibilitando o cidadão de observar como são gastos os proventos que saem de seu próprio bolso, novamente espelhando a estrutura de sigilo imposta no manejo de dados no Brasil.

O Ministério do Desenvolvimento Social também apresenta realidade de ineficácia na implementação da LAI em seu site. Apesar de haver, para consulta, uma lista com os tipos de licitações, várias páginas referentes são inexistentes ou estão expiradas. Além disso, o conteúdo está desatualizado desde 2016 e o portal nem sequer faz referência a outro sítio eletrônico para encontrar a informação desejada.

A manutenção desses comportamentos é nefasta para a democracia pois, como explicitado por Batista (2012, p. 218), nessas posturas “estão implícitas várias negações que convergem num processo de exclusão do outro, de sua história, de sua memória, da garantia de indenização, do direito de conhecer dados sobre a própria vida.” Conforme entendimento da autora, impõe-se, assim, o interesse do Estado e seus gestores sobre a sociedade, resultando na obscuridade de informações, alienação geral, “uma violência que priva a sociedade do direito de questionar” (BATISTA, 2012, p. 218).

Em seguida, verificaram-se resultados positivos. O site do Ministério da Educação possui sistema satisfatório de acesso a dados sobre as licitações. Com disposição de fácil compreensão, o portal possibilita que o cidadão pesquise com filtros de "data”, "relevância”, "palavra-chave”, bem como por intervalos de tempo. Além disso, as informações são atualizadas desde 2008. A mesma situação é encontrada no Ministério da Indústria, Comércio Exterior e Serviços, Ministério da Cultura, Ministério da Saúde, Ministério do Esporte e Ministério do Meio Ambiente.

Também satisfatório é o resultado acerca do Ministério da Ciência, Tecnologia, Inovações e Comunicações, que possui, além dos mesmos atributos acima referidos, possibilidade de busca por 
“tipo” de licitação, tal qual os sites do Ministério de Minas e Energia, Ministério do Planejamento, Desenvolvimento e Gestão e Ministério do Trabalho.

Exemplo parcialmente positivo encontra-se no portal do Ministério da Justiça, à exceção de que alguns arquivos sobre pregões realizados estão corrompidos, impossibilitando o acesso aos dados respectivos. O Ministério da Fazenda também apresentou um ponto negativo, limitando a observação a intervalos de 15 dias, tornando o acesso difícil ao cidadão, uma vez que fragmenta muito a pesquisa.

Assim como no item analisado anteriormente, o Ministério da Defesa remete suas informações ao Portal da Transparência, constando em seu site tão somente o caminho para encontrar o dado no sítio remetido. Diferentemente do Ministério da Agricultura, Pecuária e Abastecimento, uma vez que o site deste apenas remete ao canal da Transparência, sem auxiliar o cidadão em como obter o dado. O portal da Presidência da República, da mesma forma, transfere a responsabilidade em disponibilizar as informações acerca de licitações. Além disso, possui, entre os sites pesquisados, a pior disposição para navegação em rede, pois impõe dificuldades ao internauta para encontrar os dados ou mesmo ser redirecionado para outro sítio eletrônico.

O panorama evidenciado a partir da análise do acesso à informação das licitações nos órgãos pesquisados gera algumas preocupações. Apesar de poucos órgãos apresentarem problemas graves, verifica-se que poucos cumprem integralmente os preceitos legais de acesso.

Assim, não se mostra plenamente implementada a Lei de Acesso à Informação também em relação ao terceiro item do estudo. Uma vez que a informação pública, quando acessível à sociedade, afeta o exercício dos gestores a partir do controle social exercido, bem como reconfigura a estrutura de participação social (BATISTA, 2012), deve-se zelar para que todo dado sem o status sigiloso esteja em mãos do povo. Mais do que isso, o conteúdo necessita estar conciso e claro, oferecendo ao interessado o aparato necessário para melhor avaliar os atos de governo, tais como o emprego de recursos públicos em licitações, e não apenas seu resultado (CARDOSO, 1998).

Em sequência, parte-se para a análise dos dados acerca de contratos.

\subsection{A PUBLICIDADE SOBRE OS CONTRATOS}

A previsão legislativa do dever de publicizar dados sobre os contratos firmados pelos órgãos públicos encontra-se no art. $7^{\circ}$, $\S 3^{\circ}$, inciso V, do Decreto $n^{\circ} 7.724 / 2012$, que regulamenta a Lei de 
Acesso à Informação. É o instrumento utilizado para firmar negócios jurídicos entre o ente público e o contratado, posterior ao processo licitatório.

Dessa maneira, mostra-se salutar o estudo acerca da divulgação de informações sobre os contratos firmados pelos órgãos do Poder Executivo Federal, pois a partir desse conteúdo examinamse as obrigações firmadas pelo gestor público, bem como as contrapartidas executadas pelo contratado. Mais do que isso, a publicização desses dados permite a fiscalização quanto à correta execução do objeto pactuado, a qualidade da licitação e os valores empregados pela gestão pública.

Quantos aos resultados da análise, assim como no item anterior, é possível encontrar realidades positivas na estrutura de alguns sites. No entanto, como será exposto, a maioria não implementa plenamente os mandamentos da legislação de acesso. Os portais, por exemplo, não disponibilizam atalho para solicitar, via correio eletrônico, a íntegra do instrumento de contrato e seus aditivos, limitando o acesso do cidadão.

O Ministério da Fazenda, diferentemente dos outros órgãos, não remete ao canal da Transparência. Leva, no entanto, o cidadão ao "Painel de Compras”, onde dispõe de filtros por ano, mês de assinatura do contrato e unidade federativa em que foi realizado. Isso se mostra uma estratégia positiva, uma vez que facilita a investigação pormenorizada dos termos dos instrumentos firmados.

O Ministério da Ciência, Tecnologia, Inovações e Comunicações, em situação semelhante ao examinado nas licitações, oferece meio de pesquisa próprio, facultando ao cidadão filtrar a busca por data e conteúdo, bem como por termos e expressões que possam constar no contrato desejado. Situação semelhante foi verificada nos sites do Ministério do Turismo, Ministério de Minas e Energia, Ministério do Trabalho e Ministério do Meio Ambiente. Somam-se a esses o Ministério do Desenvolvimento Social e Ministério da Cultura, com destaque para a disponibilização dos termos aditivos e prorrogações dos contratos, inexistente nos demais.

O portal do Ministério dos Transportes, Portos e Aviação Civil é eficaz, porém apresenta algumas limitações no acesso aos dados. Isso porque exibe os contratos apenas por anos e por números, dificultando a filtragem por conteúdo e objeto. Realidade análoga foi examinada no Ministério da Indústria, Comércio Exterior e Serviços.

Os portais do Ministério da Educação, do Ministério da Agricultura, Pecuária e Abastecimento e da Presidência da República não disponibilizam o conteúdo sobre os negócios jurídicos firmados nas suas administrações, remetendo tão somente para a página principal do Portal da Transparência, relegando o cidadão à necessidade de buscar o conteúdo por si.

O Ministério da Justiça, do mesmo modo, não expõe em seu site os materiais acerca de contratos. Todavia, instrui o interessado a encontrar os dados no canal de transparência do Governo 
Federal. Ainda mais específico, o Ministério da Defesa divide a instrução em tópicos, facilitando a localização da informação no site remetido, apesar de não cumprir com a obrigação de divulgação em seu próprio portal.

O portal do Ministério do Esporte disponibiliza um hiperlink para acesso ao conteúdo de outro site. No entanto, o link é falho, levando o interessado a uma página inexistente, ferindo o art. $7^{\circ}$, inciso I, da LAI.

O Ministério das Relações Exteriores não disponibiliza os dados de contratos firmados desde 2016. No caso do Ministério da Saúde, a negligência na renovação do conteúdo se dá desde 2015. A desatualização dessas informações fere o art. $7^{\circ}$, inciso IV, da LAI, constituindo-se prática danosa à sociedade, privada do acesso aos negócios jurídicos praticados nos últimos anos pelos órgãos.

O que se percebe é que o acesso eficiente à informação no Brasil, exemplificado pela análise dos dados de contratos nos órgãos públicos, ainda não se tornou regra. Raros foram os portais que apresentaram de maneira completa os itens necessários para a devida prestação de dados. A partir do momento em que se destaca a maioria negativamente e apenas a minoria dos portais com estruturas eficazes, o direto de acesso à informação é deixado de lado, com consequente fortalecimento do princípio do segredo. É o que entendem Canela e Nascimento (2009, p. 27):

O acesso a informações em poder do Estado não pode ser encarado como boa prática administrativa ou ação progressiva desta ou daquela administração. Ele deve ser compreendido, tanto pelos funcionários e agentes do Estado como pela população em geral, como um direito fundamental do cidadão.

É pertinente o entendimento dos autores, pois a disponibilização de conteúdo em poder do Estado à população permite o empoderamento dessa e a legitimação daquele, embaraçando o abuso de poder, ao mesmo tempo que inclui o povo na formação política da sociedade (CANELA; NASCIMENTO, 2009). O resultado é o desconhecimento dos cidadãos acerca do cenário coletivo do País, a impossibilidade de debate sobre os assuntos de caráter geral e que interferem na realidade social. A falta de transparência nos atos estatais e a incompetência da máquina pública a deixam cada vez mais distante da permeabilidade do controle social.

É o que se percebe a partir da observação realizada, que, apesar de não possuir o objetivo de exaurir o conteúdo, verificou ser ineficaz a implementação da Lei n ${ }^{\circ}$ 12.527/2011 nos órgãos do Poder Executivo Federal. O resultado é um sistema político altamente burocrático, que obstaculiza o acesso às informações e serviços públicos ao cidadão. Como consequência tem-se a manutenção de práticas políticas autoritárias e que muitas vezes geram favorecimentos para algumas parcelas da população 
em detrimento de outras, o que, como adverte Paes de Paula (2005, p. 44), resulta na ilegitimidade do Estado que mantém o segredo como regra.

\section{CONSIDERAÇÕES FINAIS}

Resta evidente o caráter garantidor de direitos com que a implementação da cultura de acesso é revestida - ou poderia ser - no Brasil. A utilização das Tecnologias de Informação e Comunicação e a nova visão de governo, adquirindo caráter eletrônico e aberto mostram-se instrumentos capazes de fazer a diferença no cenário de - pouca - participação social na política, pois capacitam o cidadão a controlar e fiscalizar o Estado. Não só isso; possibilitam que o povo possa discutir de modo informado e se envolver na mudança do espectro nacional, exercendo novas dimensões de cidadania e ampliando a consciência enquanto sociedade.

Ademais, a implementação da LAI no Brasil, uma vez que seja movida de maneira competente, mostra-se essencial no combate à corrupção, na inserção de um modelo de gestão compartilhada de Estado e na maior transparência das ações governamentais, modificando a atual realidade de acesso à informação pública no País.

No tocante à análise dos dados de pesquisa, a conclusão foi de ineficácia na implementação da Lei $\mathrm{n}^{0}$ 12.527/2011 nos portais do Poder Executivo Federal. Foram detectadas diversas inconsistências na implantação da norma nos sites, não havendo, atualmente, superação da cultura do sigilo na administração de conteúdo público no Brasil.

Averiguou-se que, em regra, os portais analisados transferem a responsabilidade de disponibilização das informações a outras páginas. Como consequência, torna-se limitado o acesso do cidadão, uma vez que aumenta a complexidade do procedimento, pois impõe uma despadronização na maneira como é exposta a informação. Essa conjuntura exemplifica a tendência dos órgãos públicos em manter como regra a cultura do sigilo, dispersando o conteúdo referente às suas atividades em diversos portais.

Em relação às receitas, 12 dos 19 órgãos examinados não tratam do assunto. Não publicizam, portanto, informações acerca dos valores recebidos, bem como sua origem - omissão que viola os princípios de transparência pública. O resultado é a obstaculização da implementação da LAI, impactando nos objetivos de combate à corrupção e incentivo à participação popular.

Quanto às licitações e contratos, os resultados apresentados foram menos gravosos; ainda assim, insatisfatórios. Isso porque as falhas encontradas na aplicação da normativa prejudicam o 
acesso de informações relevantes ao cidadão, pois é por meio das licitações e contratos que o Poder Público destina parcela dos recursos públicos.

Portanto, mesmo com a sanção da lei, há um longo percurso a ser alcançado até a competente aplicação do direito fundamental de acesso a dados públicos, previsto na Constituição do Brasil.

A realidade encontrada a partir da pesquisa afasta o povo do exercício da cidadania e do debate necessário sobre a melhor forma de administração pública, sendo essencial o combate à cultura do segredo, enraizada na política brasileira. Além disso, é relevante haver mudança cultural, pois apenas a positivação da normativa não possui poder suficiente para aplicar os princípios basilares da LAI. Isso porque se percebe não haver ações públicas suficientes para facilitar o processo de implementação da lei, impossibilitando que os objetivos previstos pelo legislador sejam aplicados efetivamente no meio social.

Diante disso, não há a plena efetivação do direito de acesso a dados e, consequentemente, tal exclusão fragiliza ainda mais os grupos sociais que historicamente são marginalizados pela falta de informação, visto que, sem informes completos e compreensíveis, não há condições de demandar pela satisfação dos direitos fundamentais que lhes são negados.

Para mudar o panorama evidenciado no estudo, é importante, primeiramente, que os objetivos norteadores dos agentes responsáveis pela aplicação da LAI não sejam inalcançáveis ou intransponíveis, na medida em que uma ação pública deva refletir as possibilidades da realidade social. A cultura de acesso à informação, por mais que seja fundamental para o desenvolvimento social em um país, é uma atividade meio, ou seja, não possui um fim em si.

Como visto, a mera existência de lei específica não tem o poder de mudar realidades, considerando todas as notícias de práticas de corrupção reveladas recentemente pelas mais variadas agências de notícias brasileiras e estrangeiras. Percebe-se que a Lei de Acesso à Informação Pública ainda não foi capaz de efetuar uma mudança significativa no problema de falta de transparência no País.

O direito à informação, em um cenário de governança aberta, auxiliado pelas TIC, tem mostrado potencial para ser uma importante ferramenta de luta contra a corrupção, buscando um modelo de gestão compartilhada de Estado, mediante a transparência das ações públicas. Portanto, conclui-se ser fundamental que concomitantemente à vigência da lei sejam realizadas ações de sensibilização nos órgãos públicos integrantes de todos os Poderes, com vistas à promoção da cultura de maior abertura institucional, à sociedade, dos atos da gestão orçamentária. Tal medida pode ser implementada conjuntamente com ações de abertura dos órgãos públicos e de sua transparência passiva e ativa. 
A verdadeira mudança ocorre na inserção da política de acesso no meio público, uma vez que sua principal função é dar suporte para que o cidadão conheça sobre sua realidade. Na mesma linha, a transparência não garante que a máquina pública estará livre de corrupção. No entanto, sem a publicidade dos atos públicos e, consequentemente, sem o controle social, a política brasileira tornase indefesa à má gestão.

Além de legislação que traduza a realidade social de maneira clara e da criação de ações públicas, é necessária a aplicação dessas ações, o que não ocorre de forma homogênea no Brasil. A escolha do modo pelo qual essa política de informação será empregada deve levar em conta o contexto no qual a organização está inserida. Deve-se ter em mente que essa implantação é complexa e é latente considerar a realidade social vivida, bem como suas perspectivas futuras.

Trata-se de atuações que condizem com o direito pautado na LAI, possibilitando procedimentos administrativos e rotinas a serem seguidas por quem detém as informações coletivas, a fim de incorporar na sociedade o direito de acesso. Munir o povo com informações é essencial, mas não suficiente.

O Estado deve impulsionar a população a uma participação ativa e discussão embasada para tomada de decisões. A gestão da política de publicização de dados requer uma mudança na cultura organizacional do Brasil, uma vez que nem as TIC e nem a legislação de abertura são suficientes para mudar o panorama de sigilo.

É importante, ainda, dentro do contexto trabalhado, a padronização do Serviço de Informações ao Cidadão, produzindo bancos contendo as informações mais constantes nos pedidos, facilitando o acesso e reduzindo o número de solicitações com o mesmo teor de informação.

Além disso, é salutar a atualização dos dados nos portais, tornando-os mais transparentes, em uma exposição de fácil assimilação ao cidadão, bem como uma maior concentração de dados nos próprios sites dos órgãos pesquisados, de modo a facilitar o empoderamento popular enquanto participante na política nacional. Movimentações como essas podem facilitar o processo de apropriação da lei por parte da sociedade, fator que auxiliaria na erradicação da cultura do sigilo.

Isso porque, a partir do momento que as informações expressam o cenário vivido no meio social, bem como as ideologias predominantes, é salutar que estejam colocadas ao cidadão de modo organizado. Há não só uma clara necessidade de aplicar a política de publicidade de informação, mas também de aplicá-la facilitando o acesso, com linguagem não complicada, arquivos virtuais ou físicos confiáveis e inúmeras outras ações simples que facilitam a aproximação do povo com sua história.

Conjuntamente à conquista de um desimpedido direito de acesso à informação, deve ser assegurada a busca por uma organização estatal que torne cultural a regra da publicidade. Políticas 
de cunho informacional devem permitir que a sociedade se ocupe ativamente dos espaços públicos de discurso, como participante capaz de fazer a diferença no cenário nacional.

O objetivo da LAI e da luta contra a cultura do segredo é desmantelar a prerrogativa dos governantes de concentrarem o controle das informações e, consequentemente, da formulação de políticas públicas. A publicidade como regra permite a inclusão, na deliberação a respeito do interesse público, dos setores marginalizados.

É vital, portanto, que, em uma sociedade heterogênea como a brasileira, diferentes visões sejam expostas, salvaguardadas com o devido embasamento e presentes em um espaço público transparente. O diálogo entre o povo e o Estado é o cerne da democracia, a liberdade de expressão é instrumento dessa relação. Por sua vez, para que haja essa liberdade, não há outro modo senão a devida implementação de políticas de publicidade, acompanhadas do cumprimento da Lei de Acesso à Informação no Brasil.

A partir dessas realizações, haverá maior abertura das instituições políticas, além de maior interação da sociedade para construção do processo político democrático. Apenas assim se pode pensar em direito de acesso como instrumento de desenvolvimento social, real exercício da cidadania.

\section{REFERÊNCIAS}

ARTICLE19. [Artigo 19]. Repressão às escuras. Uma análise sobre transparência em assuntos de segurança pública e protestos. [S. l.], 2017. Disponível em: https://bit.ly/2Og9VEP. Acesso em: 25 abr. 2018.

BATISTA, Carmem Lúcia. Informação pública: controle, segredo e direito de acesso. Intexto, Porto Alegre, n. 26, p. 204-222, jul. 2012. Disponível em: https://bit.ly/30r4zZP. Acesso em: 10 out. 2018.

BERNARDES, Marciele Berger; SANTOS, Paloma Maria; ROVER, Aires José. Ranking das prefeituras da região Sul do Brasil: uma avaliação a partir de critérios estabelecidos na Lei de Acesso à Informação. Revista de Administração Pública, Rio de Janeiro, v. 49, n. 3, p. 761792, jun. 2015. Disponível em: https://bit.ly/3br0JWV. Acesso em: 24 set. 2017.

BOBBIO, Norberto. $O$ futuro da democracia. Uma defesa das regras do jogo. Rio de Janeiro: Paz e Terra, 1997.

BONAVIDES, Paulo. Ciência Política. 10. ed. São Paulo: Malheiros Editores, 1997.

BONAVIDES, Paulo. Teoria do Estado. São Paulo: Malheiros, 2008.

BRASIL. Decreto no 5.687, de 31 de janeiro de 2006. Promulga a Convenção das Nações Unidas contra a Corrupção, adotada pela Assembléia-Geral das Nações Unidas em 31 de outubro de 2003 e 
assinada pelo Brasil em 9 de dezembro de 2003. Disponível em: https://bit.ly/38oaOCc. Acesso em: 2 jul. 2019.

BRASIL. Lei no 12.527/2011 - Lei de Acesso à Informação. Disponível em: https://bit.ly/30o3vG6. Acesso em: 18 maio 2019.

BRASIL. Ministério da Agricultura, Pecuária e Abastecimento. Disponível em: http://www.agricultura.gov.br/. Acesso em: 18 ago. 2018.

BRASIL. Ministério da Ciência, Tecnologia, Inovações e Comunicações. Disponível em: http://www.mctic.gov.br/portal. Acesso em: 18 ago. 2018.

BRASIL. Ministério da Cultura. Disponível em: http://www.cultura.gov.br/. Acesso em: 19 nov. 2018.

BRASIL. Ministério da Defesa. Disponível em: https://www.defesa.gov.br/. Acesso em: 18 ago. 2018.

BRASIL. Ministério da Educação. Disponível em: http://portal.mec.gov.br/. Acesso em: 8 ago. 2018.

BRASIL. Ministério da Fazenda. Disponível em: http://www.fazenda.gov.br/. Acesso em: 28 set. 2018.

BRASIL. Ministério da Indústria, Comércio Exterior e Serviços. Disponível em: http://www.mdic.gov.br/. Acesso em: 18 ago. 2018.

BRASIL. Ministério da Justiça. Disponível em: https://www.justica.gov.br/. Acesso em: 18 ago. 2018.

BRASIL. Ministério da Saúde. Disponível em: http://portalms.saude.gov.br/. Acesso em: 8 ago. 2018.

BRASIL. Ministério de Minas e Energia. Disponível em: http://www.mme.gov.br/. Acesso em: 9 out. 2018.

BRASIL. Ministério do Planejamento, Desenvolvimento e Gestão. Disponível em: http://www.planejamento.gov.br/. Acesso em: 15 out. 2018.

BRASIL. Ministério do Desenvolvimento Social. Disponível em: http://mds.gov.br/. Acesso em: 2 nov. 2018.

BRASIL. Ministério do Esporte. Disponível em: http://www.esporte.gov.br/. Acesso em: 27 nov. 2018.

BRASIL. Ministério do Meio Ambiente. Disponível em: http://www.mma.gov.br/. Acesso em: 27 nov. 2018. 
BRASIL. Ministério do Trabalho. Disponível em: http://trabalho.gov.br/. Acesso em: 15 out. 2018.

BRASIL. Ministério do Turismo. Disponível em: http://www.turismo.gov.br/. Acesso em: 25 set. 2018.

BRASIL. Ministério dos Transportes, Portos e Aviação Civil. Disponível em: http://www.transportes.gov.br. Acesso em: 23 set. 2018.

BRASIL. Ministérios das Relações Exteriores. Disponível em: http://www.itamaraty.gov.br/ptBR/. Acesso em: 1 out. 2018.

BRASIL. Portal da Transparência. Disponível em: https://bit.ly/3cePujt. Acesso em: 2 maio 2019.

BRASIL. Presidência da República. Disponível em: http://www2.planalto.gov.br/. Acesso em: 13 dez. 2018.

CALDERÓN, César; LORENZO, Sebastián (Coord.). Open Government. Gobierno Abierto. Alcalá la Real: Algón Editores, 2010. Disponível em: https://bit.ly/2OiGyll. Acesso em: 30 set. 2018.

CANELA, Guilherme; NASCIMENTO, Solano (Coord.). Acesso à informação e controle social das políticas públicas. Brasília: ANDI, 2009. Disponível em: https://bit.ly/3rxl9Dp. Acesso em: 23 nov. 2018.

CARDOSO, Fernando Henrique. Reforma do Estado. In: BRESSER-PEREIRA, L. C.; SPINK, P. K. (Org.). Reforma do Estado e administração pública gerencial. Rio de Janeiro: Editora FGV, 1998. p. 15-19.

CASTELLS, Manuel. A Sociedade em Rede: do Conhecimento à Política. In: CARDOSO, Gustavo; CASTELLS, Manuel. A Sociedade em Rede: do Conhecimento à Acção Política. [Brasília]: Imprensa Nacional - Casa da Moeda, [2006]. p. 17-30. Disponível em: https://bit.ly/30rkY0q. Acesso em: 2 set. 2018.

CONTROLADORIA-GERAL DA UNIÃO (CGU). Declaração de Governo Aberto. Brasília, 2011. Disponível em: https://bit.ly/3t3O4PL. Acesso em: 12 dez. 2018.

CONTROLADORIA-GERAL DA UNIÃO (CGU). Secretaria de Prevenção da Corrupção e Informações Estratégicas. Controle Social, orientações aos cidadãos. Brasília, 2008.

DE LA RUE, Letícia Almeida. A Lei de Acesso à Informação no Poder Legislativo brasileiro dentro do contexto da sociedade informacional: perspectivas para a democracia. In: ROVER, Aires José; SIMÃO FILHO, Adalberto; PINHEIRO, Rosalice Fidalgo (Org.). Direito e novas tecnologias. v. 1. 1. ed. Florianópolis: FUNJAB, 2013. p. 86-109. Disponível em: https://bit.ly/3qBOpYs. Acesso em: 12 ago. 2018. 
DENHARDT, Janet Vinzant; DENHARDT, Robert B. The new public service: serving, not steering. Nova York: M. E. Sharpe, 2003. Disponível em: https://bit.ly/38pG4R7. Acesso em: 4 set. 2018.

FERREIRA, Sérgio Guimarães; ARAÚJO, Erika. Modernização da gestão. E-governo: o que ensina a experiência internacional. Informe SF/E, [s. l.], n. 17, Secretaria para Assuntos Fiscais (SF), BNDES, n. 17, agosto 2000.

KHAN, Abdul Waheed. Prefácio. In: MENDEL, Toby. Liberdade de informação: um estudo de direito. 2. ed. Brasília: UNESCO, 2009. Disponível em: https://bit.ly/3rwzEY2. Acesso em: 9 jul. 2018.

LÉVY, Pierre. Cibercultura. São Paulo: Editora 34, 1999.

MARTINHÃO, Maximiliano Salvadori (Coord.). TIC Governo Eletrônico. Pesquisa Sobre o Uso das Tecnologias de Informação e Comunicação no Setor Público Brasileiro. São Paulo: Comitê Gestor da Internet no Brasil, 2018. Disponível em: https://bit.ly/3vazgR6. Acesso em: 25 ago. 2018.

MARTINS JÚNIOR, Wallace Paiva. Transparência administrativa. Publicidade, motivação e participação popular. São Paulo: Saraiva, 2004.

MELLO, Marcelo Pereira de; CALLEGARI, José Antônio. Ouvidoria: Direito Fundamental de Acesso à Justiça e defesa da cidadania. In: Congresso Internacional Interdisciplinar em Sociais e Humanidades, Niterói, 2012.

MENDEL, Toby. Liberdade de informação: um estudo de direito comparado. 2. ed. Brasília: UNESCO, 2009. Disponível em: https://bit.ly/3kXWpBA. Acesso em: 18 ago. 2018.

MOREIRA NETO, Diogo de Figueiredo. Mutações do direito administrativo. Rio de Janeiro: Renovar, 2000.

ORGANIZAÇÃO DAS NAÇÕES UNIDAS (ONU). United Nations E-government survey 2016: e-government in support of sustainable development. 2016. Disponível em: https://bit.ly/38n8NpV. Acesso em: 17 ago. 2018.

PAES DE PAULA, Ana Paula. Administração pública brasileira entre o gerencialismo e a gestão social. RAE - Revista de Administração de Empresas, São Paulo, v. 45, n. 1, p. 36-49, jan.-mar. 2005. Disponível em: https://bit.ly/3tgmjDR. Acesso em: 16 jul. 2018.

REDES sociais e mídias tradicionais são as fontes de informação com mais influência na escolha do presidente em 2018. Edeal Group. 4 jul. 2017. Disponível em: https://bit.ly/2N4TASW. Acesso em: 4 ago. 2018.

SOUSA, Patrícia Lima. A implementação da Lei de Acesso à Informação no Ministério do Planejamento: a atuação do serviço de informações ao cidadão. 2014. 29 f. Trabalho de Conclusão de Curso (Especialização em Gestão Pública) - Escola Nacional de Administração Pública (ENAP), Brasília, 2014. Disponível em: https://bit.ly/30tq7VC. Acesso em: 16 ago. 2018. 
WERTHEIN, Jorge. A sociedade da informação e seus desafios. Ciência da Informação, Brasília, v. 29, n. 2, p. 71-77, maio/ago. 2000. Disponível em: https://bit.ly/30rmAr0. Acesso em: 11 jul. 2018. 